\title{
Estratégia\&Negócios
}

ISSN 1984-3372

http://www.portaldeperiodicos.unisul.br/index.php/EeN/

\section{A IMPULSIVIDADE NAS COMPRAS PELA INTERNET}

\section{THE IMPULSIVITY IN INTERNET PURCHASE}

\section{Luciene Diana Siqueira}

Mestranda em Administração pela Universidade Municipal de São Caetano do Sul.

E-mail: luciene.siqueira@attglobal.net

\section{Adriana Domingues Marques de Castro}

Mestranda em Administração pela Universidade Municipal de São Caetano do Sul.

E-mail: adriana.castro@fsa.br

\section{Julio de Carvalho}

Mestrando em Administração pela Universidade Municipal de São Caetano do Sul.

E-mail: carvalhojulio@ig.com.br

\section{Milton Carlos Farina}

Professor do PPGA da Universidade Municipal de São Caetano do Sul. Doutor em Administração pela Universidade de São Paulo - USP.

E-mail: milton.farina@uscs.edu.br

Recebido em 21/01/2012. Aprovado em 27/03/2012. Disponibilizado em 25/05/2012.

Avaliado pelo Sistema double blind review

R. eletr. estrat. neg., Florianópolis, v.5, n.1, p. 253-279, jan./abr.2012

http://portaldeperiodicos.unisul.br/index.php/EeN/index
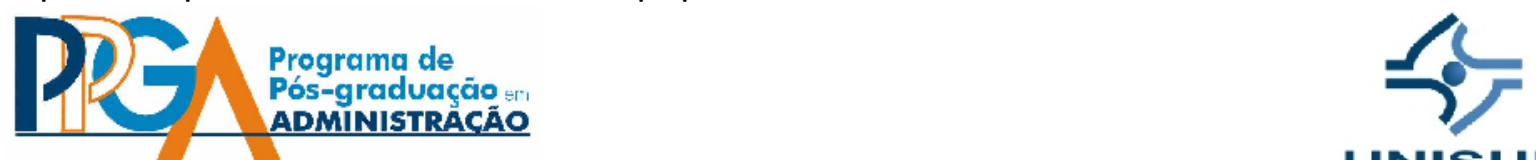

UNISUL

CCopyright 2008 UNISUL-PPGA/Estratégia e Negócios. Todos os direitos reservados. Permitida citação parcial, desde que identificada a fonte. Proibida a reprodução total. Em caso de dúvidas, consulte o editor:

ademar.unisul@gmail.com; (48) 3229-19 


\section{RESUMO}

Este artigo investiga a influência do gênero, idade, renda e posse de cartão de crédito sobre a impulsividade no processo de compras pela internet. A compra impulsiva é um tipo de compra não planejada, definida como a tendência do consumidor a comprar espontaneamente, sem reflexão, de forma imediata, dominado pela atração emocional e absorvido pela promessa de gratificação imediata. O fenômeno compra por impulso associado ao varejo online ainda é relativamente novo e de extrema relevância. $\mathrm{O}$ comércio eletrônico apresenta crescimento de aproximadamente $40 \%$ ao ano, tendo atingido 23 milhões de e-consumidores no Brasil, em 2010. Este estudo foi realizado com base num levantamento de campo junto a instituições de ensino superior na região do Grande $A B C / S P$, cuja amostra foi composta por 336 estudantes de cursos de graduação e pós-graduação. De acordo com a análise dos resultados, a única variável que apresentou influência sobre o comportamento impulsivo nas compras online foi renda pessoal, não se verificando o mesmo para as demais variáveis estudadas. O escore médio de impulsividade para a amostra, que poderia variar entre 11 e 77, foi 24,84 pontos. Isto sugere que o comportamento de compra pela internet dos estudantes analisados é de orientação predominantemente não impulsiva.

Palavras-chave: Impulsividade. Comportamento do consumidor. Comércio eletrônico.

\section{INTRODUÇÃO}

Entender o porquê de o consumidor comprar determinado produto em detrimento de outros é importante para as empresas que concorrem no mercado business to consumer (B2C). O estudo do comportamento do consumidor está centrado no seu processo de compra (CHURCHILL JR; PETER, 2010) e o entendimento das etapas da decisão da compra é de suma importância para a área de marketing e para o gerenciamento estratégico das organizações, pois é o ponto de partida para elaboração de estratégias de R. eletr. estrat. neg., Florianópolis, v.5, n.1, p. 253-279, jan./abr. 2012 
segmentação e posicionamento no mercado, envolvendo todos os componentes de marketing: produto, promoção, preço e distribuição.

Os momentos críticos do processo de compra acontecem dentro do ambiente de loja, no qual a maior parte das decisões ocorre (SOLOMON, 2002). Após selecionar e visitar uma loja, o cliente pode realizar uma compra planejada, não planejada ou por impulso (SHETH et al., 2001, p. 665). As compras não planejadas podem ser para reposição de estoque. Neste caso, o cliente não havia pensado em comprar naquele momento, apesar de utilizar o produto de forma regular. A exposição ou uma promoção especial foi o fator decisivo para que ele realizasse a compra. Uma compra não planejada pode se referir a um novo produto pelo qual o cliente ainda não tinha necessidade. A compra por impulso também é uma compra não planejada, na qual o cliente adquire itens espontaneamente, sem premeditação, abreviando todo o processo decisório de compra. A compra por impulso pode ser estimulada pela ocasião, disparada pela vitrine do produto ou promoção no ponto de venda (BLACKWELL; MINIARD; ENGEL, 2008). É resultado de influências ambientais e fatores psicodinâmicos internos (YOUN; FABER, 2000).

A evolução da internet possibilita e estimula o surgimento de novos mercados e, sem dúvida, esta tem se tornado um dos principais canais de vendas e distribuição das organizações. A Apple iTunes Music Store e a Symantec são exemplos de empresas que exploram esses novos mercados utilizando a internet como um dos principais canais de vendas. Seu modelo de negócio é essencialmente digital, ou seja, a comercialização e a entrega de seus produtos ou serviços são realizadas pela própria internet. É a forma mais pura de comércio eletrônico (CE), uma vez que todo o processo do negócio é realizado online (RAPPA, 2010). O modelo mercantil direto também focaliza a internet como seu principal canal de vendas; a Dell é um exemplo clássico de empresa produtora de mercadorias, que se utiliza da web como canal direto de venda para o consumidor final, eliminando total ou parcialmente os intermediários (E-COMMERCE. ORG.BR).

Outro modelo de negócio inovador que explora a internet como principal canal de vendas é a corretagem, chamada de facilitador de negócios na internet. São sites que facilitam e estimulam a realização de transações por meio da manutenção de um ambiente virtual, colocando em contato e aproximando fornecedores e potenciais compradores. 
Dentro desta categoria, estão os shoppings virtuais e os leilões online (ECOMMERCE.ORG.BR). As empresas Amazon e eBay, respectivamente, são exemplos clássicos destas subcategorias.

Costa e Larán (2003) acreditam que o comportamento de compra por impulso somente ocorrerá com a mesma intensidade nas lojas virtuais e físicas a partir do momento em que não existir mais desconfiança ou temor quanto à realização de compras pela internet. De fato, a segurança é um dos principais obstáculos ao comércio eletrônico. É a maior preocupação das empresas e dos e-consumidores. Apesar dos investimentos e dispositivos de segurança implementados, a possibilidade do e-consumidor ser lesado numa transação online continua sendo real.

Estudos acerca dos inúmeros aspectos do emergente mercado virtual necessitam de atenção, sobretudo em relação ao fato do varejo online influenciar ou não o comportamento do consumidor, da mesma forma e intensidade que o varejo tradicional.

À luz deste cenário, esta pesquisa tem como objetivo verificar se as variáveis: gênero, idade, renda familiar, renda pessoal e a posse de algum cartão de crédito afetam a impulsividade na compra realizada especificamente pela internet. Características demográficas e psicográficas do consumidor, o comportamento de consumo e compra, as características geográficas e os fatores situacionais são normalmente adotados para a segmentação de consumidores potenciais com comportamentos semelhantes. Além disso, o gênero, a idade e a renda representam um importante papel cultural (BLACKWELL; MINIARD; ENGEL, 2008). Por esta razão, tais variáveis foram adotadas para este estudo. A pesquisa também se propõe a descrever os principais produtos adquiridos pela internet por estudantes de cursos de graduação e pós-graduação da região Grande ABC/SP.

O artigo está estruturado em cinco seções. A próxima seção corresponde à fundamentação teórica. Em seguida, a metodologia de pesquisa é detalhada. Na quarta seção, demonstra-se a análise dos resultados e, por fim, são apresentadas as considerações finais, com as contribuições do estudo, suas limitações e sugestões para novas pesquisas. 


\section{REFERENCIAL TEÓRICO}

Solomon (2002) define comportamento do consumidor como o estudo dos processos envolvidos quando indivíduos ou grupos selecionam, compram, usam ou dispõem de produtos, serviços, ideias ou experiências para satisfação de suas necessidades e de seus desejos. Para Shiffman e Kanuk (2000), trata-se do estudo de como os indivíduos tomam a decisão de gastar seus recursos disponíveis (tempo, dinheiro, esforço) em itens relacionados ao consumo.

Comprar e consumir, no entanto, não significam exatamente a mesma coisa. Para Solomon (2002), numa situação de consumo, consideram-se fatores que vão além das características da pessoa e do produto, que influenciam a compra e/ou uso de produtos e serviços.

Diversas são as razões que levam as pessoas às compras. Na visão de Blackwell, Miniard e Engel (2008), as razões podem ser pessoais ou sociais, e se diferenciam conforme o quadro 1. Segundo Solomon (2002), efeitos situacionais também influenciam o ato de comprar e podem apresentar características comportamentais (como entreter amigos) ou perceptivas (sentir-se deprimido ou pressionado pelo tempo).

Quadro 1- Por que as pessoas compram?

\begin{tabular}{l|l}
\hline Motivos Pessoais & Motivos Sociais \\
\hline Papel exercido & Experiências sociais fora de casa \\
\hline Diversão & Comunicação com outras pessoas de interesses similares \\
\hline Autogratificação & Atração por grupos de amigos \\
\hline Conhecimento de novas tendências & Status e autoridade \\
\hline Atividade Física & Prazer em barganhar \\
\hline Estimulação sensorial & \\
\hline \multicolumn{2}{l}{ Fonte: Blackwell, Miniard e Engel, 2008, p. 136.}
\end{tabular}

\subsection{ASPECTOS DO COMPORTAMENTO DO CONSUMIDOR}

Para Blackwell, Miniard e Engel (2008), os processos e comportamentos de tomadas de decisão dos consumidores sofrem influência de fatores individuais, ambientais e psicológicos. Dentre os fatores ambientais, incluem-se: cultura, classe social, família, 
influências pessoais e situação. Por esta razão, características demográficas e psicográficas do consumidor, o comportamento de consumo e compra, as características geográficas e os fatores situacionais são normalmente adotados para a segmentação de consumidores potenciais com comportamentos semelhantes.

O termo cultura refere-se a ideias, valores, artefatos e outros símbolos significativos que auxiliam as pessoas em seu processo de comunicação, na visão que têm de si mesmas como membros da sociedade e de suas atitudes (BLACKWELL; MINIARD; ENGEL, 2008). Uma vez que as pessoas são criadas para seguirem as crenças, os valores e os costumes de sua sociedade e evitarem comportamentos reprováveis, a cultura exerce forte influência sobre o comportamento do consumidor (SHIFFMAN; KANUK, 2000).

Shiffman e Kanuk (2000) definem subculturas como grupos culturais distintos que formam um segmento identificável dentro de uma sociedade maior e mais complexa. São, portanto, subdivisões da mesma, baseadas em variáveis socioculturais e demográficas (nacionalidade, religião, localização geográfica, idade, raça, gênero e status profissional). Na visão deles, a discussão sobre subculturas é mais restrita do que a discussão sobre cultura, já que em vez de se examinarem as crenças, os valores e os costumes dominantes de uma sociedade inteira, trata-se daqueles compartilhados por membros de subgrupos específicos dela, pessoas de origens étnicas semelhantes, costumes, comportamentos etc.

\subsection{A IMPULSIVIDADE AO COMPRAR}

As compras por impulso relacionam-se a compras não planejadas, onde não há planejamento prévio (STERN, 1962; BLACKWELL; MINIARD; ENGEL, 2008). Segundo Blackwell, Miniard e Engel (2008), a compra por impulso é estimulada pela ocasião, disparada pela vitrine do produto ou promoção no ponto de venda, cujas características são: (1) desejo repentino e espontâneo de agir acompanhado por urgência; (2) estado de desequilíbrio psicológico no qual a pessoa pode se sentir temporariamente fora de controle; (3) princípio de um conflito e luta que é resolvido por uma ação imediata; (4) existência mínima de avaliação objetiva - domínio das considerações emocionais; (5) ausência de preocupação com as consequências. 
A compra por impulso não se confunde com o consumo compulsivo. Enquanto o impulso para comprar um item específico é temporário e se concentra em determinado produto num certo momento, o comprar compulsivo é um comportamento repetitivo, muitas vezes excessivo, como um antídoto para a tensão, ansiedade, depressão ou tédio, que é centrado no processo de comprar, e não nas compras em si (SOLOMON, 2002).

Para O'Guinn e Faber (1989), no consumo compulsivo há uma tendência a se comprar de forma repetitiva e crônica, que se torna uma resposta primária a eventos ou sentimentos negativos. Já segundo Rook e Fisher (1995), refere-se à tendência a se comprar espontânea e irrefletidamente, de forma imediata, sob domínio da atração emocional e incentivo de promessa de gratificação imediata.

A compulsão torna a atividade de compra sintomática, acompanhada por um sentimento de restrição e falta de controle, onde a função defensiva aparece claramente (VALENCE; D'ASTOUS; FORTIER, 1988). De acordo com McElroy, Phillips e Keck (1994), a compra compulsiva é um comportamento de compra incontrolável e estressante, que consome tempo e implica em dificuldades financeiras ou sociais. Rook e Hoch (1984) diferenciam a compra compulsiva da impulsiva porque esta última não resulta em consequências negativas. Além disso, estes dois tipos de compra são diferenciados pelas motivações e consequências do comportamento, e também pela frequência com que ocorrem (O'GUINN; FABER, 1988).

\subsection{CONSIDERAÇÕES SOBRE AS VARIÁVEIS: GÊNERO, IDADE, RENDA E CARTÃO DE CRÉDITO}

O gênero, a idade e a renda representam um importante papel cultural, podendo ser considerados como subculturas conforme visto anteriormente. De acordo com Blackwell, Miniard e Engel (2008), entende-se por "papel" o que é esperado de alguém que ocupa uma determinada posição, num certo contexto social. De um modo geral, todas as sociedades costumam atribuir certas características e papéis a homens e mulheres. Por esta razão, historicamente, o gênero vem sendo tratado como uma variável diferencial de segmentação. É fundamental, entretanto, considerar-se a significativa mudança observada nos papéis do 
gênero, sobretudo pelo impacto contínuo das residências com renda dupla (SHIFFMAN; KANUK, 2000).

O estudo realizado por Veludo-de-Oliveira, Ikeda e Santos (2004) aponta o gênero como um preditor do comportamento de compra compulsiva, sendo as mulheres as principais referências. Este estudo subsidiou a escolha da variável gênero para se avaliar as diferenças da compra impulsiva pela internet.

A segunda variável considerada foi a idade. Segundo Solomon (2002), apesar de pessoas da mesma faixa etária, diferirem de muitos outros modos, elas têm uma real tendência a compartilhar um conjunto de valores e experiências culturais comuns. Por esta razão, a necessidade e o interesse por um produto, normalmente, variam com a idade do consumidor.

A terceira variável escolhida foi a renda. Segundo Jeon (1990 apud Costa, 2002), quanto maior for a renda passível de ser despendida com o consumo, maior será a probabilidade de ocorrer compra por impulso. Entretanto, apesar de a renda ser uma importante variável para diferenciar segmentos de mercado, ela apenas indica a capacidade de se pagar por um produto (SHIFFMAN; KANUK, 2000). No presente estudo, a renda foi abordada sob os aspectos pessoal e familiar. Embora, geralmente, considere-se a existência de uma correlação entre estas duas variáveis, nesta pesquisa com jovens universitários elas foram tratadas individualmente para avaliar se há diferença entre a influência que cada uma delas exerce sobre a impulsividade no ato de consumo.

A última variável analisada foi a posse de cartão de crédito. O cartão de crédito está se popularizando em vários segmentos da sociedade, gerando mudanças no comportamento de grupos que não tinham acesso a esse serviço (VELUDO-DE-OLIVEIRA; IKEDA; SANTOS, 2004). Apesar do dinheiro e cheques serem ainda muito utilizados, muitos consumidores pagam com cartões de crédito, seja pela possibilidade de adiar os pagamentos ou devido à facilidade de crédito (BLACKWELL; MINIARD; ENGEL, 2008). 


\subsection{O ENVOLVIMENTO ASSOCIADO AO PROCESSO DE COMPRA}

De acordo com Blackwell, Miniard e Engel (2008), o grau de envolvimento pessoal é um fator que impacta no tipo de processo de decisão adotado pelo consumidor ao realizar suas compras. Quanto mais importância ele atribui ao produto ou serviço, mais ele se envolve no processo. Na visão desses autores, dentre os fatores que determinam o grau de envolvimento do consumidor na tomada de decisão, destacam-se:

I. fatores pessoais - o grau de envolvimento é maior quando o resultado da decisão afeta diretamente o consumidor (incluem autoconceito, saúde, beleza ou condição física);

II. fatores do produto - as marcas ou produtos tornam-se envolventes se há algum risco percebido em sua compra ou uso, seja ele físico, psicológico, de performance ou financeiro. Quanto maior o risco percebido, maior a probabilidade de alto envolvimento;

III. fatores situacionais - relativos a questões como: qual produto será comprado para uso pessoal ou para presentear alguém? Será consumido pelo comprador sozinho ou em companhia de outros? O envolvimento situacional se altera ao longo do tempo.

Segundo Blackwell, Miniard e Engel (2008), em relação à decisão de compra, os tipos de compra são assim definidos:

I. compra totalmente planejada - o produto e a marca são previamente escolhidos; ocorre normalmente quando o produto é de alto envolvimento, mas pode também ocorrer em compras de baixo envolvimento;

II. compra parcialmente planejada - há uma intenção de se comprar o produto, mas a escolha da marca, estilo ou tamanho é adiada até o momento efetivo da compra; quando o envolvimento é baixo, os consumidores costumam lançar mão de comprar uma marca que conhecem e gostam; 
III. compra não planejada - tanto o produto quanto a marca são escolhidos no ponto de venda.

Nota-se que os autores SHETH et al. (2001) incluem e diferenciam a compra por impulso como uma forma de compra não planejada.

\subsection{COMÉRCIO ELETRÔNICO}

Albertin (2004, p.15) define que Comércio Eletrônico (CE) é a realização de toda a cadeia de valor dos processos de negócio num ambiente eletrônico, através da aplicação intensa das tecnologias de comunicação e de informação (TICS), atendendo aos objetivos de negócio. Os processos podem ser realizados de forma completa ou parcial, incluindo as transações negócio a negócio (B2B), negócio a cliente (B2C), cliente a cliente (C2C) e intraorganizacional, numa estrutura predominantemente pública de fácil e livre acesso e baixo custo. Esta definição pode ser considerada a mais ampla, uma vez que o CE tem sido definido por vários autores e as definições, em sua maioria, se complementam, dado o caráter amplo desta nova aplicação de TI.

O CE iniciou-se em 1995, quando um dos primeiros portais da internet, o Netscape.com, aceitou anúncios de grandes organizações, popularizando assim a ideia de que a internet poderia ser usada como um novo canal de anúncios e vendas. No entanto, naquela época, ninguém visionou que as vendas no varejo online se tornariam uma curva de crescimento exponencial (LAUDON; LAUDON, 2010, p.375).

$\mathrm{O}$ rápido crescimento no $\mathrm{CE}$ nos anos posteriores criou uma bolha no mercado de ações, e como toda bolha, o estouro das "ponto.com" ocorreu em março de 2001. Um grande número de empresas de CE faliu neste processo, enquanto outras, como Amazon, eBay e Google tiveram resultados mais positivos, receitas aumentadas, modelos de negócios evoluídos, melhoria nos lucros e no valor de suas ações. Em 2006, o crescimento nas receitas do CE novamente tornou-se sólido nos EUA, na Europa e na Ásia (LAUDON; LAUDON, 2010).

No Brasil, o cenário não é diferente. Segundo dados da empresa E-BIT (2011), os números do CE brasileiro não param de crescer. Em 2010, 23 milhões de pessoas já haviam 
realizado pelo menos uma compra online até então (vide figura 1). Para o 1 을 semestre de 2011, a empresa estima que 4 milhões de novas pessoas farão sua primeira compra virtual, totalizando assim 27 milhões de e-consumidores.

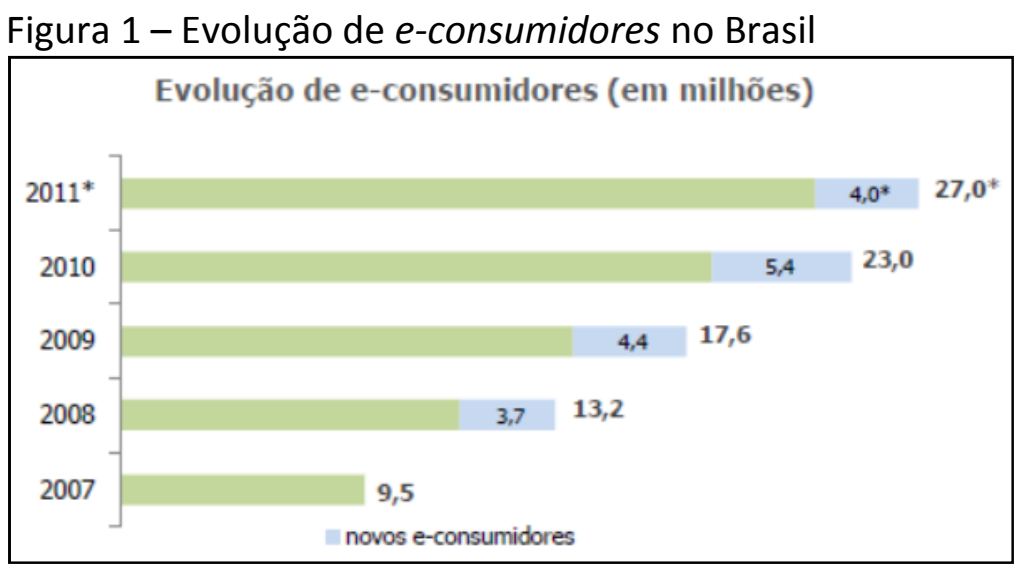

Fonte: E-BIT, 2011.

Nota: $\left({ }^{*}\right)$ previsão para o 1ㅇ. semestre/2011.

No ano de 2010, foram faturados $\mathrm{R} \$ 14,8$ bilhões em vendas de bens de consumo no CE brasileiro, o que significou um acréscimo de $40 \%$ contra os $R \$ 10,6$ bilhões registrados em 2009.

\subsubsection{Produtos mais vendidos na internet}

O processo de compra em lojas virtuais é destituído de uma série de estímulos e influências ambientais, que as lojas fisicamente constituídas possuem. Por essa razão, a maioria das aquisições realizadas pela internet, até certo tempo atrás, era de produtos hedônicos, destinados a gerar prazer, como livros e CDs (BAUMEISTER 2002 apud COSTA; LARÁN, 2003).

No entanto, o comportamento de compras dos e-consumidores mudou bastante em relação aos "primórdios da internet", com o aumento do nível de confiança dos consumidores e da maturidade do mercado virtual, aliado à entrada das lojas tradicionais de varejo no comércio eletrônico (COSTA; LARÁN, 2006). 
Atualmente, já se observam e-consumidores comprando produtos que antes eram considerados mais difíceis de serem assim adquiridos, como roupas e acessórios. Produtos estes, em que o toque ou a prova é essencial e, devido a esta característica, eram considerados pouco atraentes no comércio eletrônico (SOLOMON, 2002).

Segundo pesquisas da E-BIT (2011), tal categoria já ocupa a 6a colocação no ranking das categorias mais vendidas do setor. Há 4 anos, era apenas a 26a colocada. Nos Estados Unidos, essa categoria está entre as 3 mais vendidas no CE do país. A perspectiva para 2011 é que, assim como no mercado norte americano, a venda de moda e acessórios ganhe cada vez mais a atenção dos e-consumidores brasileiros.

Segundo os dados do E-BIT (2011), foram mais de 40 milhões de pedidos realizados no ano de 2010 via internet contra os 30 milhões realizados ano anterior. 0 ranking das categorias mais vendidas quanto ao volume de pedidos foi: eletrodomésticos (14\%), livros, assinaturas de revistas e jornais (12\%); saúde, beleza e medicamentos (12\%), informática (11\%) e eletrônicos (7\%) (E-BIT, 2011).

O valor médio das compras em 2010 foi de R\$ 373. Em 2009, este número fechou em $\mathrm{R} \$ 335$, registrando um crescimento de $11 \%$. Sugere-se que este aspecto foi diretamente afetado pelo advento da copa do mundo, com a preferência dos $e$ consumidores em adquirirem produtos de maior valor agregado, como TVs de LCD (E-BIT, 2011).

\subsubsection{O Gênero Feminino nas Compras online}

De acordo com dados do levantamento de 2010 da E-BIT, $49 \%$ dos $e$ consumidores pertencem ao público feminino e, dos novos entrantes em 2010, 55\% são pertencentes ao mesmo gênero. Os dados também revelaram que, dentre aqueles que realizam compras pela internet, as mulheres são mais escolarizadas que os homens. $53 \%$ das mulheres são, no mínimo, graduadas, contra 50\% dos homens. O tíquete médio das compras femininas aumentou de R\$ 240 em 2005 para R\$ 314 em 2010. No entanto, ele continua significativamente menor que o tíquete médio dos gastos efetuados pelos homens, de $\mathrm{R} \$$ 425 , ou seja, $35 \%$ superior ao das mulheres. 
Em relação à idade das e-consumidoras, o relatório aponta que as mulheres com idade superior a 50 anos passaram de $14 \%$ para $21 \%$ do total de compradoras, entre 2005 e 2010, denotando um aumento da senioridade das compradoras virtuais. Analisando a diferença de renda dos consumidores virtuais, percebe-se que, na faixa de renda familiar mensal de até $R \$ 3.000,00$, encontram-se $56 \%$ das mulheres que efetuaram compras em 2010, enquanto que em 2005, esta mesma faixa representava $50 \%$.

\subsubsection{O "Boom" das Compras online}

Blackwell, Miniard e Engel (2008) citam casos em que a compra online é mais eficiente: 1) quando há impossibilidade de se deslocar até a loja; 2) quando o telefonema é difícil ou não é conveniente; 3) quando se trata de compra repetida; 4) quando o consumidor está familiarizado com os produtos que estão sendo pedidos; 5) quando o consumidor não tem urgência de receber o produto; e 6) quando produtos procurados são difíceis de encontrar.

Costa e Larán (2006) afirmam que portais que propiciam uma maior interatividade e personalização na atividade de busca e aquisição de um produto pela internet são passíveis de gerar impulsos de consumo e, por sua vez, compras impulsivas. A Amazon.com é um exemplo disso, por apresentar recomendações de e-consumidores que adquiriram o mesmo item procurado. Além disso, o emprego de apelos racionais na comunicação da loja virtual pode despertar o interesse e a impulsividade do consumidor, devido aos atrativos de maior conveniência para a compra, tais como: loja aberta 24 horas; disponibilidade de estoques com maior variedade de produtos e preços inferiores aos oferecidos pelas lojas físicas.

Os novos modelos de negócio no CE também são atrativos. O mercado virtual cria oportunidades para que negócios especializados se desenvolvam (BLACKWELL; MINIARD; ENGEL, 2008). Os sites de compras coletivas são um exemplo disso, com ofertas de até $70 \%$ de desconto que duram apenas 24 horas. No Brasil, há cerca de 1.800 portais deste tipo e a perspectiva de faturamento para 2011 deve ultrapassar 1 bilhão de reais (TEIXEIRA JÚNIOR, 2011). 
Laudon e Laudon (2010) explicam que a natureza única da internet torna as tecnologias empregadas no comércio eletrônico muito mais ricas e poderosas se comparadas às tecnologias revolucionárias como o rádio, a TV e o telefone. Os autores salientam para as seguintes características da internet: 1) unicidade - a internet está disponível em todo lugar (em casa, no trabalho, em qualquer lugar via dispositivo móvel) e a qualquer tempo; 2) alcance global - a tecnologia transcende limites geográficos da Terra; 3 ) padrões universais - são os chamados padrões/protocolos de internet; 4) riqueza - há possibilidade de integração entre mensagens de texto, áudio e vídeo; 5) interatividade - a tecnologia funciona através da interatividade com o usuário; 6) densidade da informação reduz custos da informação e aumenta a qualidade; 7) personalização/customização permite serviços personalizados a serem entregues aos indivíduos/grupos; 8) tecnologia social - novos modelos de negócios habilitam a geração e distribuição de conteúdo online pelos próprios usuários e a tecnologia também provê suporte às redes sociais.

No entanto, é importante reconhecer que um dos fatores que afastam potenciais consumidores da internet é a percepção do elevado risco de realizar transações a distância, muitas vezes com provedores que não estão presentes no mundo físico (KLEIN, 2001 apud COSTA; LARÁN, 2003). Segundo pesquisas empíricas de Costa e Larán (2003), empresas que possuem atuação nos dois ambientes com a mesma marca (por exemplo: Livraria Cultura, Ponto Frio e Lojas Americanas) levam vantagem em relação àquelas que estão apenas no mundo virtual.

O comportamento de compra por impulso somente ocorrerá com a mesma intensidade em lojas virtuais e físicas a partir do momento em que não existir mais desconfiança ou temor quanto à realização de compras pela internet (COSTA; LARÁN, 2003). Pode ser que na compra coletiva, o preço baixo e o tempo finito de promoção diminuam ou anulem o temor do cliente de comprar pela internet. Os dados do Índice E-BIT/internet Segura de Confiança dos Consumidores de Comércio Eletrônico mostram que a aprovação dos usuários online foi de $86,62 \%$ durante o ano de 2010 , lembrando que o patamar de excelência definido para o índice é de $85 \%$.

Com base nesta revisão bibliográfica e nos objetivos do trabalho, as seguintes hipóteses são apresentadas: $\mathrm{H}_{1}$ : a impulsividade nas compras pela internet é influenciada R. eletr. estrat. neg., Florianópolis, v.5, n.1, p. 253-279, jan./abr. 2012 
pelo gênero; $\mathrm{H}_{2}$ : a impulsividade nas compras pela internet é influenciada pela idade; $\mathrm{H}_{3}$ : a impulsividade nas compras pela internet é influenciada pela renda familiar; $\mathrm{H}_{4}$ : a impulsividade nas compras pela internet é influenciada pela renda pessoal e $\mathrm{H}_{5}$ : a impulsividade nas compras pela internet é influenciada pela posse de algum cartão de crédito.

\section{METODOLOGIA}

Tipo da Pesquisa: exploratório-descritiva de corte transversal, operacionalizada a partir de uma survey. As pesquisas exploratórias têm como propósito proporcionar maior familiaridade com o problema, com vistas a torná-lo mais explícito ou a construir hipóteses (GIL, 2010, p.27). Uma importante característica distintiva dos estudos transversais é a de que os elementos são medidos somente uma vez durante o processo de investigação (HAIR JÚNIOR et al., 2006, p.87).

População e procedimento de amostragem: estudantes de cursos de graduação e pós-graduação de instituições de ensino superior (IES) da região do Grande ABC/SP foram definidos como a população alvo deste estudo. A amostra foi selecionada por conveniência, sendo, portanto, não probabilística. Por esta razão, as conclusões deste estudo são válidas exclusivamente para a amostra selecionada, não podendo ser generalizadas para toda a população alvo (HAIR JÚNIOR et al., 2006). A amostra foi composta por 336 estudantes de cursos de graduação e pós-graduação de diversas IES da região do Grande $A B C / S P$. No entanto, somente 215 dentre os respondentes afirmaram já ter realizado alguma compra pela internet. Por esta razão, os resultados aqui obtidos foram baseados nas respostas destes 215 respondentes.

Instrumento e coleta de dados: o questionário completo foi desenvolvido com 43 questões. $\mathrm{O}$ aspecto da impulsividade foi abordado com 11 perguntas fechadas, escala tipo Likert, variando de 1 (discordo totalmente) a 7 (concordo totalmente). Este bloco do questionário foi adaptado de Costa (2002), que empregou a escala de impulsividade de Youn 
(2000). Esta escala avalia a impulsividade com base em aspectos afetivos (necessidade de compra, emoções, gerenciamento do humor) e cognitivos (desconsideração com as consequências futuras e deliberação cognitiva). Aplicaram-se dois pré-testes do instrumento de coleta de dados, que demonstraram a necessidade de realização de diversos ajustes nas versões anteriores do questionário. A versão final do questionário foi aplicada nos meses de outubro e novembro de 2010. A opção pelo questionário como fonte de coleta baseou-se na definição de Hair Júnior et al. (2005, p.157), segundo os quais os questionários possibilitam a coleta de dados quantitativos de um número maior de indivíduos, de forma relativamente rápida e conveniente.

Um escore de impulsividade, resultante da somatória da pontuação atribuída pelo respondente a cada uma das 11 questões descritas no quadro 2, foi atribuído a cada respondente. A pontuação total de cada respondente variou de 11 a 77 pontos. Outras variáveis para descreverem o perfil do e-consumidor foram coletadas, possibilitando a identificação de potenciais subgrupos com padrões comuns.

Quadro 2 - Relação do instrumento com o construto Impulsividade de Youn (2000)

\begin{tabular}{|c|c|}
\hline Pergunta & Aspecto \\
\hline 1 - As minhas compras pela internet são planejadas. & Cognitivo \\
\hline 2 - Quando navego pela internet, costumo comprar algo somente para me sentir bem. & Afetivo \\
\hline 3-Quando navego na internet, a necessidade de comprar algo surge de repente. & Afetivo \\
\hline 4-Compro coisas pela internet mesmo não podendo pagá-las. & Cognitivo \\
\hline 5 - Eu costumo gastar meu dinheiro, comprando pela internet, assim que o recebo. & Cognitivo \\
\hline $\begin{array}{l}\text { 6- Quando tenho que fazer uma decisão de compra, geralmente levo algum tempo para } \\
\text { avaliar todos os aspectos da compra. }\end{array}$ & Cognitivo \\
\hline $\begin{array}{l}7 \text { - Frequentemente compro pela internet produtos de que não necessito, mesmo } \\
\text { sabendo } \\
\text { que possuo pouco dinheiro sobrando. }\end{array}$ & Cognitivo \\
\hline $\begin{array}{l}\text { 8- Sinto uma necessidade de comprar um item o mais rápido possível quando estou na } \\
\text { internet, para não ter a sensação de não ter comprado alguma coisa. }\end{array}$ & Afetivo \\
\hline $\begin{array}{l}9 \text { - Tenho dificuldade para controlar meus impulsos de compra quando navego na } \\
\text { internet. }\end{array}$ & Afetivo \\
\hline $\begin{array}{l}10 \text { - Mesmo quando vejo algum produto atraente na internet, penso nas consequências } \\
\text { de } \\
\text { sua compra antes de fazê-lo. }\end{array}$ & Cognitivo \\
\hline 11 - Comprar pela internet é uma forma de reduzir o estresse da vida cotidiana. & Afetivo \\
\hline
\end{tabular}

Fonte: Elaborado pelos autores, 2012.

Nota: Para efeito de análise, as perguntas 1 e 6 tiveram suas escalas invertidas. 
Análise dos dados: para tabulação, tratamento e análise estatística dos dados coletados, utilizou-se o software estatístico SPSS (versão 18). Realizou-se também uma análise comparativa entre os dados observados e os dados secundários apresentados no referencial teórico. Foram empregadas técnicas de estatística descritiva e testes de hipóteses não paramétricos (Mann-Whitney e Kruscal Wallis).

\section{RESULTADOS DA PESQUISA}

A apresentação dos resultados será feita em quatro partes: i) perfil da amostra, com os dados demográficos dos respondentes; ii) ranking dos produtos mais comprados pela internet; iii) escore de impulsividade; e, iv) associação entre o escore de impulsividade e as variáveis demográficas, através de testes de hipóteses.

Como a amostra foi selecionada por conveniência, não é probabilística e, portanto, não é possível a mensuração dos erros amostrais. Logo, os resultados apurados nesta pesquisa são válidos exclusivamente para a amostra selecionada, impossibilitando sua generalização para a população alvo.

\subsection{PERFIL DA AMOSTRA}

Dos 336 questionários aplicados, descartaram-se 121, que foram respondidos por pessoas que nunca haviam realizado compra pela internet até a data da coleta. Dos 215 questionários válidos, 103 foram respondidos por homens e 112 por mulheres.

Os dados apurados indicaram representatividade ligeiramente mais alta de mulheres e-consumidoras ( $52,1 \%$ contra $47,9 \%$ de homens), enquanto que pelos dados do $\mathrm{E}$ BIT (2011), 49\% dos e-consumidores em 2010 foram do gênero feminino contra 51\% do gênero masculino. No entanto, considerando que, segundo esta mesma fonte, $55 \%$ dos novos entrantes no CE, em 2010, foram do público feminino, pode-se considerar que a diferença aqui apurada não contradiz os dados secundários. 
A análise da faixa etária da amostra aponta a predominância de jovens entre 20 a 29 anos (63,3\%). A segunda maior concentração verificada foi na faixa etária de 30 a 39 anos (19,1\% dos respondentes), seguida da faixa até 19 anos (9,8\%). Isso se justifica pelo fato da amostra ser constituída por estudantes de cursos de graduação e pós-graduação. Na faixa de 40 a 49 , observaram-se $4,7 \%$ e na faixa acima de 49 anos, 3,1\%.

Quanto à condição de trabalho, verificou-se que: $77,2 \%$ dos respondentes trabalham como empregados ou autônomos; 8,4\% estão desempregados; $10,2 \%$ são estagiários ou não trabalham por opção; $2,8 \%$ são empregadores e $1,4 \%$ exercem algum outro tipo de atividade remunerada.

Observou-se uma distribuição variada da renda familiar da amostra. Conforme a tabela 1 , há concentração de cerca de $20 \%$ dos respondentes em cada uma das faixas 3, 4, 5 e 6 (rendas entre $\mathrm{R} \$ 1.530,00$ e $\mathrm{R} \$ 10.000,00)$. Quanto à renda pessoal, quase metade da amostra $(49,8 \%)$ possui renda entre $\mathrm{R} \$ 511,00$ e $\mathrm{R} \$ 1.530,00$.

Tabela 1 - Perfil da amostra quanto ao rendimento pessoal e familiar

\begin{tabular}{l|l|l|l|l|l}
\hline Faixa & \multicolumn{1}{|c|}{ Rendimento } & $\begin{array}{l}\text { Renda } \\
\text { Pessoal }\end{array}$ & $\%$ & $\begin{array}{l}\text { Renda } \\
\text { Familiar }\end{array}$ & $\%$ \\
\hline 1 & Até R\$ 510,00 & 14 & 6,5 & 2 & 0,9 \\
\hline 2 & Maior que R\$ 510,00 a R\$ 1.530,00 & 107 & 49,8 & 18 & 8,4 \\
\hline 3 & Maior que R\$ 1.530,00 a R\$ 2.550,00 & 44 & 20,5 & 46 & 21,4 \\
\hline 4 & Maior que R\$ 2.550,00 a R\$ 3.570,00 & 17 & 7,9 & 43 & 20,0 \\
\hline 5 & Maior que R\$ 3.570,00 a R\$ 5.100,00 & 13 & 6,0 & 40 & 18,6 \\
\hline 6 & Maior que R\$ 5.100,00 a R\$ 10.000,00 & 8 & 3,7 & 39 & 18,1 \\
\hline 7 & Maior que R\$ 10.000,00 a R\$ 20.000,00 & - & - & 10 & 4,7 \\
\hline 8 & Maior que R\$ R\$ 20.000,00 & - & - & 3 & 1,4 \\
\hline & Não informado & 12 & 5,6 & 14 & 6,5 \\
\hline & Total & 215 & 100,0 & 215 & 100,0 \\
\hline
\end{tabular}

Fonte: Elaborado pelos autores, 2012.

A pesquisa também mostrou que $32,1 \%$ das mulheres têm renda familiar entre $\mathrm{R} \$ 2.550,00$ e $\mathrm{R} \$ 3.570,00$, enquanto $22,3 \%$ dos homens estão nessa mesma faixa. Em contrapartida, 25,2\% dos homens estão na faixa número 6 (de $\mathrm{R} \$ 5.100,00$ a $\mathrm{R} \$ 10.000,00$ ), onde se concentram apenas $11,6 \%$ das mulheres. Apesar da diferença da renda familiar entre os gêneros, os dados da pesquisa E-BIT (2011) apontam que a renda familiar feminina cresceu cinco pontos percentuais entre 2005 e 2010. 
Quanto ao cartão de crédito, $80 \%$ da amostra responderam possuir ao menos um cartão de crédito e, dentre estes, 91\% são os próprios titulares.

\subsection{RANKING DOS PRODUTOS MAIS VENDIDOS NO COMÉRCIO ELETRÔNICO}

Os respondentes foram solicitados a responder, dentre os produtos listados abaixo, quais já haviam sido adquiridos pela internet. O ranking das cinco categorias mais citadas pelos 215 respondentes foi, conforme a tabela 2: livros e revistas, telefonia, produtos de informática e acessórios, ingressos e passagens.

Tabela 2 - Produtos mais comprados

\begin{tabular}{l|l|l}
\hline Categoria de Produtos & Qtde. & $\%$ \\
\hline Livros e Revistas (didáticos e não didáticos) & 113 & 52,56 \\
\hline Telefonia (aparelhos fixos, celulares e acessórios) & 100 & 46,51 \\
\hline Produtos de Informática e acessórios & 96 & 44,65 \\
\hline Ingressos (shows, cinema, teatro, eventos etc) & 95 & 44,19 \\
\hline Passagens (Rodoviárias, Ferroviárias, Aéreas) & 87 & 40,47 \\
\hline CD’s, DVD's, games e similares & 82 & 38,14 \\
\hline $\begin{array}{l}\text { Eletrodomésticos / Eletroportáteis (refrigerador, fogão, batedeira } \\
\text { etc) }\end{array}$ & 66 & 30,70 \\
\hline Produtos Eletrônicos (TV, Som e Vídeo) & 51 & 23,72 \\
\hline Medicamentos & 49 & 22,79 \\
\hline Cosméticos e Perfumaria & 39 & 18,14 \\
\hline Downloads pagos (de música, filme, livros, jogos, software) & 35 & 16,28 \\
\hline Pacotes turísticos & 35 & 16,28 \\
\hline Brinquedos & 29 & 13,49 \\
\hline Calçados, bolsas e acessórios de vestuário & 28 & 13,02 \\
\hline Artigos esportivos (inclusive vestuário e acessórios) & 27 & 12,56 \\
\hline Roupas & 26 & 12,09 \\
\hline Artigos de Papelaria & 23 & 10,70 \\
\hline Móveis & 10 & 4,65 \\
\hline Compras de supermercado & 7 & 3,26 \\
\hline Fonte: Elaborado pelos autoress
\end{tabular}

Fonte: Elaborado pelos autores.

As dez categorias de produtos mais citadas neste estudo confirmam os produtos mais vendidos pela internet, elencados pela pesquisa E-BIT (2011): eletrodomésticos, livros, assinaturas de revistas e jornais, saúde, beleza e medicamentos, informática e eletrônicos. 


\subsection{ESCORE DE IMPULSIVIDADE}

Neste tópico, são apresentados os resultados da distribuição dos e-consumidores conforme a somatória do escore de impulsividade.

Dos 215 e-consumidores da amostra, cinco foram considerados "missing", pois não responderam ao bloco de questões relacionadas à impulsividade. Portanto, restaram 210 respondentes válidos para este construto; sendo 101 homens e 109 mulheres.

A média da pontuação de impulsividade foi de 24,36 para o público feminino e de 25,36 para o masculino. O escore médio de impulsividade para toda a amostra ficou em 24,84. É válido lembrar que a variação do escore é de no mínimo 11 e no máximo 77.

\subsection{TESTE DE HIPÓTESES}

Para verificar se as variáveis gênero, idade, renda e posse de cartão de crédito influenciam a impulsividade, isto é, a compra não planejada e, neste caso, realizada pela internet, definiram-se previamente as seguintes hipóteses:

$\mathrm{H}_{1}$ : a impulsividade é influenciada pelo gênero;

$\mathrm{H}_{2}$ : a impulsividade é influenciada pela idade;

$\mathrm{H}_{3}$ : a impulsividade é influenciada pela renda familiar;

$\mathrm{H}_{4}$ : a impulsividade é influenciada pela renda pessoal;

$\mathrm{H}_{5}$ : a impulsividade é influenciada pela posse de algum cartão de crédito.

A seguir, verificou-se o tipo de teste a ser adotado. Segundo Hair Júnior et al. (2005, p. 289), quando os dados são mensurados por escala intervalar ou de razão, a amostra é grande e os dados são coletados de populações que apresentam distribuição normal, devem-se utilizar testes paramétricos, caso contrário, devem-se empregar testes não paramétricos. Assim, considerando-se a natureza da escala atribuída às variáveis gênero (nominal), posse de cartão de crédito (nominal) e renda (ordinal), os testes não paramétricos são os mais apropriados para o teste das hipóteses $\mathrm{H}_{1}, \mathrm{H}_{3}, \mathrm{H}_{4}$ e $\mathrm{H}_{5}$. A análise que leva em R. eletr. estrat. neg., Florianópolis, v.5, n.1, p. 253-279, jan./abr. 2012 
conta a variável idade será feita por faixas etárias e, consequentemente, para se testar a hipótese $\mathrm{H}_{2}$ serão utilizados testes não paramétricos.

Em síntese, para testar as cinco hipóteses mencionadas acima, adotaram-se os seguintes testes não paramétricos: Wilcoxon-Mann-Whitney para as hipóteses $H_{1}$ e $H_{5}$, e Kruskal-Wallis para as hipóteses $\mathrm{H}_{2}, \mathrm{H}_{3}$ e $\mathrm{H}_{4}$.

A respeito da influência do gênero sobre a impulsividade $\left(H_{1}\right)$, definiu-se a seguinte hipótese nula: " $\mathrm{H}_{0}$ : a impulsividade não é influenciada pelo gênero". A estatística do teste de Mann-Whitney realizado apresentou valor igual a 5308,00 e p-value igual a 0,655 . Sendo este maior que $5 \%$, aceitou-se $\mathrm{H}_{0}$. O mean-rank do escore de impulsividade apresentou valor 107,45 para os homens e 103,70 para as mulheres. Concluiu-se que o fato de o respondente ser homem ou mulher não afeta sua impulsividade em compras realizadas pela internet.

Para a realização dos testes das demais hipóteses, definiram-se suas respectivas hipóteses nulas, a exemplo da definida para o teste $\mathrm{H}_{1}$. A estatística do teste de KruskalWallis para $\mathrm{H}_{2}$ apresentou valor de 6,177 e p-value igual a 0,186 maior que 5\%. Assim, aceitou-se $\mathrm{H}_{0}$, concluindo-se que a idade do respondente não influencia a impulsividade em compras realizadas pela Internet.

A estatística do teste de Kruskal-Wallis para $\mathrm{H}_{3}$ apresentou valor 5,115 com $p$ value igual a 0,646 , maior que $5 \%$. Aceitou-se também $\mathrm{H}_{0}$, concluindo-se que a renda familiar do respondente não influencia a impulsividade em compras realizadas pela internet.

Já a estatística do teste de Kruskal-Wallis para $\mathrm{H}_{4}$ apresentou o valor 14,988 e $p$ value igual a 0,010, inferior ao nível de significância 0,05. Diferentemente dos testes anteriores, rejeitou-se $\mathrm{H}_{0}$. Analisando os escores de impulsividade (mean-rank), observam-se valores de impulsividade maiores para as faixas de renda pessoal de $\mathrm{R} \$ 1.530,00$ a $\mathrm{R} \$$ $2.550,00(114,50)$, de $\mathrm{R} \$ 2.550,00$ a $\mathrm{R} \$ 3.570,00(108,18)$ e de $\mathrm{R} \$ 3.570,00$ a $\mathrm{R} \$ 5.100,00$ $(116,54)$. Para as faixas salariais inferiores com renda de até $R \$ 510,00$ e entre $R \$ 510,00$ e R\$ 1.530,00 observaram-se, respectivamente, os valores mean-rank 69,42 e 97,56. Curiosamente, os entrevistados com renda pessoal entre $\mathrm{R} \$ 5.100,00$ e $\mathrm{R} \$ 10.000,00$ apresentaram mean-rank no valor de 46,88 . Com base na amostra pesquisada e nos seus resultados, constata-se que a impulsividade está relacionada com faixas salariais R. eletr. estrat. neg., Florianópolis, v.5, n.1, p. 253-279, jan./abr. 2012 
intermediárias, não sendo expressiva nas faixas menores ou superiores. Desta forma, conclui-se que a impulsividade, na amostra selecionada, é influenciada pela renda pessoal e não pela renda familiar.

A estatística do teste de Mann-Whitney realizado para a última hipótese $\left(\mathrm{H}_{5}\right)$ apresentou valor igual a 2.645,50 e p-value igual a 0,352. Sendo este maior que 5\%, aceitouse $H_{0}$. O mean-rank apresentou valor 100,25 para os entrevistados que possuem cartão de crédito como titular ou como dependente, e valor 110,39 para quem não possui cartão de crédito. Concluiu-se que o fato do respondente possuir ou não cartão de crédito, não influencia na impulsividade em compras realizadas pela internet.

\section{CONSIDERAÇÕES FINAIS}

A amostra selecionada apresentou o seguinte perfil: $47,9 \%$ de homens e $52,1 \%$ de mulheres; maioria com renda pessoal de até $\mathrm{R} \$ 1.530,00$; idade entre 20 e 29 anos; exerce atividade remunerada; $80 \%$ possuem algum cartão de crédito; adquirem em lojas virtuais, principalmente, livros, celulares e produtos de informática.

A pesquisa apontou que as variáveis gênero, idade, renda familiar e a posse de algum cartão de crédito não se mostraram influenciadoras sobre o comportamento de compra por impulso no varejo online. Ao contrário do que se esperava, entretanto, a renda pessoal influenciou o comportamento impulsivo dos respondentes, sobretudo daqueles com renda pessoal entre $\mathrm{R} \$ 1.530,00$ e $\mathrm{R} \$ 5.100,00$ (60,0\% dos casos). Este fato talvez possa ser explicado pelo fato de se tratarem de jovens universitários, que passam a ter mais autonomia financeira a partir de seu ingresso no mercado de trabalho, que comumente costuma ocorrer após seu ingresso na universidade. Até então, o quanto gastavam dependia, em grande parte, da aprovação ou concordância de seus pais ou mantenedores. A partir do momento que passam a ter sua própria renda, talvez passem a ter mais 'poder' para decidir quanto gastam, com o quê gastam e como gastam seus próprios recursos. 
Conforme os resultados da análise amostral, o cartão de crédito não se mostrou como elemento estimulante da impulsividade nas compras realizadas pela internet. Isso também foi verificado por Roberts e Jones (2001) em seu estudo acerca de compra compulsiva, segundo o qual o cartão de crédito foi considerado um elemento moderador entre as atitudes do comprador e a compra compulsiva, sendo utilizado de forma responsável e restrita.

Já no estudo de Veludo-de-Oliveira, Ikeda e Santos (2004) foi identificado que os jovens com maior pontuação no construto compulsividade são, em sua maioria, os mesmos que afirmaram utilizar o cartão de forma mais intensa. Embora o cartão de crédito seja uma forma de pagamento que está se popularizando nas classes sociais mais baixas, nesta pesquisa, com $80 \%$ dos respondentes com posse de cartão de crédito, o elemento não se mostrou fator influenciador na impulsividade nas compras online.

Segundo dados do E-BIT (2011), as mulheres representaram 55\% dos novos entrantes nas compras online em 2010. Veludo-de-Oliveira, Ikeda e Santos (2004) apontam o gênero feminino como um preditor no comportamento de compra compulsiva. Contudo, nesta pesquisa, observou-se que o fato de ser homem ou mulher não influenciou na pontuação de impulsividade em compras realizadas pela internet.

O escore médio de impulsividade para toda a amostra ficou em 24,84. É válido lembrar que a variação do escore é de no mínimo 11 e no máximo 77 . Isto sugere que o comportamento dos estudantes analisados, ao realizarem compras pela internet, é de orientação predominantemente não impulsiva.

Considerando que a amostra foi selecionada de forma intencional, trata-se de amostra não probabilística. Portanto, os resultados aqui apurados são válidos exclusivamente para os elementos amostrais, não sendo possível a sua generalização para a população alvo. Desta forma, os referidos resultados servem apenas de subsídios para futuras pesquisas associadas ao tema comportamento do consumidor, tanto no comércio eletrônico como nas lojas físicas.

Este estudo utilizou um referencial teórico na escolha de suas variáveis e se baseou em estudos empíricos anteriores acerca do tema, porém, tanto esta pesquisa como os estudos citados acerca dos temas "compra por impulso" (COSTA; LARÁN, 2003, 2006) e R. eletr. estrat. neg., Florianópolis, v.5, n.1, p. 253-279, jan./abr. 2012 
"a influência do cartão de crédito na compra compulsiva" (VELUDO-DE-OLIVEIRA; IKEDA; SANTOS, 2004; ROBERTS; JONES,2001) não esgotaram totalmente o assunto, abrindo caminhos para futuras vertentes de pesquisa.

Tratando especificamente da compra por impulso na internet, a escassez de estudos sobre sua ocorrência e suas peculiaridades no comércio eletrônico traduz-se em campo inexplorado e fértil para a condução de um grande número de pesquisas futuras. Deste modo, torna-se interessante a realização de estudos adicionais que: (1) avaliem melhor a correlação entre a influência das rendas familiar e pessoal sobre o comportamento do consumidor e, mais especificamente, seus efeitos sobre a impulsividade ao comprar, seja por meio da internet ou não; (2) envolvam outras variáveis que possam influenciar a tomada de decisão no processo de compra do e-consumidor, como por exemplo: estado civil; tempo de acesso à Internet; conhecimento e habilidade em tecnologias web.

Sob o ponto de vista acadêmico, este estudo buscou contribuir para uma melhor compreensão acerca do comportamento de jovens consumidores em compras realizadas pela internet e, mais especificamente, sobre a impulsividade atrelada a seu processo de decisão de compra. Sugere-se, ainda, a possível evidência de um importante nicho de mercado, a quem os gestores de marketing de empresas que operam na internet podem procurar dirigir suas campanhas publicitárias, levando em consideração suas preferências, seus gastos médios e sua suposta autonomia financeira.

\section{THE IMPULSIVITY IN INTERNET PURCHASE}

\section{ABSTRACT}

This paper investigates the influence of gender, age, income, and possession of a credit card on the impulsivity in e-commerce. The impulse buying is a type of unplanned purchase, defined as a consumer tendency to buy spontaneously, without reflection, in an immediate way, dominated by emotional attraction and absorbed by the promise of instant gratification. The impulse buying phenomenon, associated to the online retail is still 
relatively new and extremely important. E-commerce has grown by approximately $40 \%$ per year, reaching 23 million e-customers in Brazil in 2010. This study was based on a field survey with institutions of higher education in the Greater $A B C$ region of São Paulo, whose sample consisted of 336 students in undergraduate and postgraduate level. According to the results analysis, the unique variable that showed influence on impulsive behavior in online retail is personal income. This outcome was not noticed in the other variables studied. The impulsivity mean score of the sample was 24,84 points, which could vary between 11 and 77. This suggests that the buying behavior on internet of analyzed students is guidance predominantly non-impulsive.

Key-words: Impulsivity. Consumer behavior. E-commerce.

\section{REFERÊNCIAS}

ALBERTIN, L. A. Comércio eletrônico: modelo, aspectos e contribuições de sua aplicação. 5. ed. São Paulo: Atlas, 2004.

BLACKWELL, R. D.; MINIARD, P. W.; ENGEL, J. F. Comportamento do consumidor. 9. ed. São Paulo: Cengage Learning, 2008.

CHURCHILL JR., G. A.; PETER, J. P. Marketing: criando valor para os clientes. São Paulo: Saraiva, 2010.

COSTA, F. Influências ambientais e comportamento de compra por impulso: um estudo em lojas físicas e virtuais. 213 f. Tese (Doutorado em Administração). Faculdade de Economia, Administração e Contabilidade - Universidade de São Paulo. São Paulo, 2002.

COSTA, F. C. X; LARÁN, J. A. Influências do ambiente de loja e o comportamento de compra por impulso: a visão dos clientes de lojas virtuais. Revista de Administração da Universidade de São Paulo, São Paulo, v. 41, n. 1, p. 96-106, jan.-mar./2006.

COSTA, F. C. X; LARÁN, J. A compra por impulso em ambientes on-line. Revista de Administração de Empresas, São Paulo, v. 43, n. 4, out.-dez./2003. 
E-BIT INFORMAÇÃO. Webshoppers 23a edição. Disponível em:

<http://www.webshoppers.com.br/webshoppers/WebShoppers23.pdf>. Acesso em: 28 jun. 2011.

E-COMMERCE.ORG.BR. Disponível em <http://www.ecommerce.org.br/modelo de negocio.php>. Acessado em 23/mar/2012.

GIL, A. C. Como elaborar projetos de pesquisa. 5. ed. São Paulo: Atlas, 2010.FABER. R.;

O'GUINN, T. Compulsive consumption and credit abuse. Journal of Consumer Policy, v. 11, n. 1, p. 97-109, mar. 1988.

HAIR JÚNIOR, J. F.; BABIN, B.; MONEY, A. H.; SAMOUEL, P. Métodos de pesquisa em administração. Porto Alegre: Bookman, 2005.

LAUDON, K. C.; LAUDON, J. P. Management information systems: organization and technology. 10 ed. Upper Saddle River: Prentice Hall, 2010.

MCELROY, S.; PHILLIPS, K.; KECK, P. Obsessive compulsive spectrum disorder. Journal of Clinical Psychiatry, v. 55, p. 33-51, 1994.

RAPPA, M. Business Models on the Web: Managing the digital enterprise, 2010. Disponível em <http://digitalenterprise.org/models/models.html>. Acessado em 23/03/2012.

ROBERTS, J.; JONES, E. Money attitudes, credit card use, and compulsive buying among American college students. The Journal of Consumer Affairs, v. 35, n. 2, p. 213-41, Winter 2001.

ROOK, D.; FISHER, R. Normative influences on impulsive buying behavior. Journal of Consumer Research, v. 22, p. 305-13, Dec. 1995.

ROOK, D.; HOCH, S. Consuming impulses. Advances in consumer research, v. 12, p. 36-40, 1984.

SHETH, J. N.; MITTAL, B.; NEWMAN, B. I. Comportamento do cliente: indo além do comportamento do consumidor. São Paulo: Atlas, 2001.

SHIFFMAN, L. G.; KANUK, L. L. Comportamento do consumidor. 6 ed. Rio de Janeiro: LTC, 2000.

SOLOMON, M. R. O comportamento do consumidor: comprando, possuindo e sendo. 5 ed. Porto Alegre: Bookman, 2002. 
STERN, H. The significance of impulse buying today. Journal of Marketing, v. 26, p. 59-63, Apr. 1962.

TEIXEIRA JÚNIOR, S. O novo jeito de vender. Revista Exame. São Paulo, p. 22, 15 jun. 2011.

VALENCE, G.; D'ASTOUS, A.; FORTIER, L. Compulsive buying: concept and measurement. Journal of Consumer Policy, v. 11, p. 419-33, 1988.

VELUDO-DE-OLIVEIRA, T. M.; IKEDA, A. A.; SANTOS, R. C. Compra compulsiva e a influência do cartão de crédito. Revista de Administração de Empresas, São Paulo, v. 89, jul.-set./2003.

YOUN, S. The dimensional structure of consumer buying impulsivity: measurement and validation. 188 f. Tese (Doutorado em Administração). University of Minnessota. Mineapolis, 2000.

YOUN, S.; FABER, R. Impulse buying: its relation to personality traits and cues. In: Advances in Consumer Research, 2000. Proceedings. Association for Consumer Research, 2000. 